\title{
COVID-19 and Rheumatic Diseases: It Is Time to Better Understand This Association
}

\author{
Claudia D.L. Marques ${ }^{1}$ (D) on behalf of the ReumaCoV Brasil Study Group
}

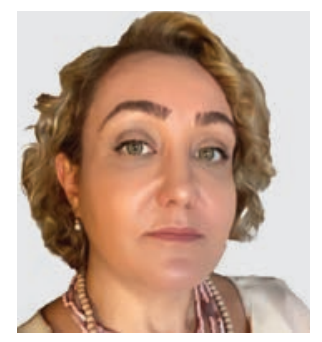

The coronavirus disease 2019 (COVID-19; caused by the SARS-CoV-2 virus), which by the end of 2019 was completely unknown to clinicians, brought uncertainties and challenges never before experienced in the modern era. Since the World Health Organization declared the pandemic on March 11, $2020^{1}$, more than 50,000,000 confirmed cases have been reported worldwide, and more than 1,200,000 individuals have died from the disease ${ }^{2}$.

In this scenario, many clinical questions have emerged from a rheumatologic standpoint: Are patients with immune-mediated rheumatic diseases (IMRD) more likely to get infected by SARS-CoV-2? Will patients with rheumatic diseases develop more severe forms of COVID-19? How should we manage immunosuppressors and biological therapy? Is there a chance of reactivation of IMRD after COVID-19? Will a SARS-CoV-2 infection trigger an autoimmune disease? To date, these questions remain unanswered.

Although patients with IMRD are known to be at higher risk of infection-attributed mainly to disease activity, comorbidities, and immunosuppressive therapy - the first published papers addressing COVID-19 in patients with IMRD, based on the clinical information published up to that time, indicated there was no consistent evidence that these patients were at higher risk compared to those with other comorbidities ${ }^{3,4}$. Since then, numerous papers about COVID-19 in patients with IMRD have been published, but there are still many unanswered questions.

The first question that has not yet been fully answered is related to the prevalence of COVID-19 in the IMRD popula-

This study is supported by grants from the National Council for Scientific and Technological Development $(\mathrm{CNPq})$ and from the Brazilian Society of Rheumatology.

${ }^{1}$ C.D. Marques, MD, PhD, Adjunct Professor of Rheumatology, Federal University of Pernambuco (UFPE), Recife, Pernambuco, Brazil. CDM reports personal fees from Janssen, Novartis, and AbbVie. Address correspondence to Dr. C.D. Marques, Hospital das Clinicas, Universidade Federal de Pernambuco. Avenida Professor Moraes Rego, $s / n-$ Recife PE - CEP 50670-901 - Brazil.Email: claudia.reumatologia@gmail.com. tion. The results of initial published studies showed comparable rates to those in the general population, and even lower rates in some studies ${ }^{5,6,7,8}$. However, a recent Italian study with 1641 patients with IMRD, from 3 Italian geographical areas with different prevalence of COVID-19, showed significantly higher rates of SARS-CoV-2 infection compared to the general Italian population, mainly due to patients' increased susceptibility to infections and by the high exposure to the virus at medical facilities before the restriction measures on individual movement ${ }^{9}$. Additionally, higher percentages of COVID-19 were observed in patient cohorts with connective tissue diseases, especially systemic lupus erythematosus ${ }^{10,11}$.

The second still-unanswered question is related to COVID-19 severity in IMRD. Faye, et al, as described in this issue of The Journal of Rheumatology ${ }^{12}$, conducted a retrospective cohort study of patients hospitalized with COVID-19, comparing their outcomes to patients with autoimmune diseases and age- and sex-matched controls in New York (USA) during the first months of the pandemic. The primary outcome was a composite of adverse events comprising death, intubation, and admission to an intensive care unit (ICU); the secondary outcome was time to in-hospital death. Among 1186 patients hospitalized with COVID-19 during the study period, 62 patients with autoimmune diseases were identified, with rheumatoid arthritis being the most frequent. The results demonstrated that this group of patients with autoimmune diseases was not at an increased risk for ICU admission, intubation, or death; instead, age and presence of comorbidities were the primary predictors of adverse outcomes.

Although the study is well analyzed, these results should be interpreted with caution and should not be generalized to patients with IMRD worldwide. The sample size is small and is contaminated with other disorders outside the spectrum of rheumatic diseases. In addition, there is no information on disease activity at the time of the SARS-CoV-2 infection. As has occurred in other studies of COVID-19 in IMRD performed at the beginning of the pandemic, it is probably a bias of inclusion.

See COVID-19 and Autoimmune Disease, page 454 
A growing body of evidence has shown that the evolution of COVID-19 in patients with IMRD may be more severe, with worse outcomes, particularly in studies with larger samples. Gianfrancesco, et a $l^{13}$, from the COVID-19 Global Rheumatology Alliance, found that although most individuals with rheumatological diseases or on immunosuppressive therapies recover from COVID-19, exposure to moderate- to high-dose glucocorticoids (GC) was associated with a higher risk of hospitalization. Anti-tumor necrosis factor therapy was associated with a decreased risk of hospitalization in patients with rheumatic disease. Freites Nuñez, et al ${ }^{14}$ observed a high percentage of patients with autoimmune inflammatory rheumatic diseases and COVID-19-related hospital admission. The patients were mainly elderly, with comorbidities and a systemic autoimmune condition. Ugarte-Gil, et al ${ }^{15}$ showed that Latin American patients with IMRD had a higher rate of acute respiratory distress syndrome (ARDS) and used GC more frequently and at a higher dose, although their mortality rate was similar to that of patients from the rest of the world.

The third question is the association between the use of corticosteroids (CS) and immunosuppressive drugs, and COVID-19 outcomes. In the study by Faye, et $a l^{12}$, two results are related to the use of CS and deserve to be highlighted: (1) unlike other studies, chronic CS use was not associated with adverse outcomes; and (2) inpatient initiation of CS or hydroxychloroquine (HCQ) was associated with adverse outcomes. Evidence arising from larger cohorts of patients with IMRD has associated the chronic use of GC with worse COVID-19 outcomes ${ }^{13,16,17,18}$. Patients with IMRD treated with high-dose CS are at significant risk of other serious infections ${ }^{19}$. In addition to this higher susceptibility, these patients can potentially develop a more severe course of infection due to the variety of metabolic and cardiovascular complications related to cortisol excess ${ }^{20}$. Thus, it is expected that this association actually exists, and the lack of this evidence in some studies is probably a result of different populations in different scenarios.

Although the studies that evaluated the use of HCQ have not demonstrated its effectiveness as a protective or therapeutic agent ${ }^{21}$, its use also seems to have no association with worse outcomes ${ }^{22,23}$. Some studies using CS in the acute phase of COVID-19 have also shown their effectiveness in controlling inflammation markers, particularly in cases of ARDS ${ }^{24,25}$. Thus, the association of worse outcomes with intrahospital use of CS and HCQ could be related to its use in more severe patients, perhaps late, in an attempt to improve the patient's condition, when there was little knowledge about the treatment of COVID-19.

Nine months have passed since the beginning of the COVID-19 pandemic, and the amount of information produced has been impressive and frighteningly fast. However, evidence of COVID-19 risks and outcomes in patients with IMRD is still limited, and any conclusions at this moment will be precipitated and unsafe. More research in the field is necessary, including epidemiological studies, prospective cohorts, and appropriately controlled clinical trials. At this stage, it is impossible to draw any conclusions regarding differences in COVID-19 risks and outcomes across different autoimmune diseases and the various immunomodulatory therapies used for them. Therefore, we must continue to find information to better understand the interface between COVID-19 and IMRD.

\section{REFERENCES}

1. World Health Organizaiton. WHO Director-General's opening remarks at the media briefing on COVID-19 - 11 March 2020. [Internet. Accessed November 25, 2020.] Available from: www.who.int/director-general/speeches/detail/ who-director-general-s-opening-remarks-at-the-media-briefing-oncovid-19---11-march-2020

2. Johns Hopkins University of Medicine Coronavirus Resource Center. 2020 [updated 2020; cited 2020 Nov, 9th]; Available from: coronavirus.jhu.edu/map.html

3. Figueroa-Parra G, Aguirre-Garcia GM, Gamboa-Alonso CM, Camacho-Ortiz A, Galarza-Delgado DA. Are my patients with rheumatic diseases at higher risk of COVID-19? Ann Rheum Dis 2020;79:839-40.

4. Favalli EG, Ingegnoli F, De Lucia O, Cincinelli G, Cimaz R, Caporali R. COVID-19 infection and rheumatoid arthritis: faraway, so close! Autoimmun Rev 2020;19:102523.

5. Zhong J, Shen G, Yang H, Huang A, Chen X, Dong L, et al. COVID-19 in patients with rheumatic disease in Hubei province, China: a multicentre retrospective observational study. Lancet Rheumatol 2020;2:e557-64.

6. Favalli EG, Agape E, Caporali R. Incidence and clinical course of COVID-19 in patients with connective tissue diseases: a descriptive observational analysis. J Rheumatol 2020;47:1296.

7. Quartuccio L, Valent F, Pasut E, Tascini C, De Vita S. Prevalence of COVID-19 among patients with chronic inflammatory rheumatic diseases treated with biologic agents or small molecules: a population-based study in the first two months of COVID-19 outbreak in Italy. Joint Bone Spine 2020;87:439-43.

8. Aries P, Iking-Konert C. No increased rate of SARS-CoV-2 infection for patients with inflammatory rheumatic diseases compared with the general population in the city of Hamburg (Germany). Ann Rheum Dis 2020 Aug 7 (E-pub ahead of print).

9. Ferri C, Giuggioli D, Raimondo V, L’Andolina M, Tavoni A, Cecchetti R, et al; COVID-19 \& ASD Italian Study Group. COVID-19 and rheumatic autoimmune systemic diseases: report of a large Italian patients series. Clin Rheumatol 2020;39:3195-204.

10. Mathian A, Mahevas M, Rohmer J, Roumier M, Cohen-Aubart F, Amador-Borrero B, et al. Clinical course of coronavirus disease 2019 (COVID-19) in a series of 17 patients with systemic lupus erythematosus under long-term treatment with hydroxychloroquine. Ann Rheum Dis 2020;79:837-9.

11. Bozzalla Cassione E, Zanframundo G, Biglia A, Codullo V, Montecucco C, Cavagna L. Covid-19 infection in a northern-Italian cohort of systemic lupus erythematosus assessed by telemedicine. Ann Rheum Dis 2020;79:1382-3.

12. Faye AS, Lee KE, Laszkowska M, Kim J, Blackett JW, McKenney AS, et al. Risk of adverse outcomes in hospitalized patients with autoimmune disease and covid-19: a matched cohort study from New York City. J Rheumatol 2021;48:454-62.

13. Gianfrancesco M, Hyrich KL, Al-Adely S, Carmona L, Danila MI, Gossec L, et al. Characteristics associated with hospitalisation for covid-19 in people with rheumatic disease: data from the covid-19 global rheumatology alliance physician-reported registry. Ann Rheum Dis 2020;79:859-66.

14. Freites Nuñez DD, Leon L, Mucientes A, Rodriguez-Rodriguez L, Font Urgelles J, Madrid Garcia A, et al. Risk factors for hospital 
admissions related to covid-19 in patients with autoimmune inflammatory rheumatic diseases. Ann Rheum Dis 2020;79:1393-9.

15. Ugarte-Gil MF, Marques CD, Alpizar-Rodriguez D, Pons-Estel GJ, Xibille-Friedmann D, Paiva E, et al. Characteristics associated with covid-19 in patients with rheumatic disease in Latin America: data from the Covid-19 Global Rheumatology Alliance physician-reported registry. [Internet. Accessed November 25, 2020.] Available from: globalrheumpanlar.org/node/254

16. Brenner EJ, Ungaro RC, Gearry RB, Kaplan GG, Kissous-Hunt M, Lewis JD, et al. Corticosteroids, but not TNF antagonists, are associated with adverse covid-19 outcomes in patients with inflammatory bowel diseases: results from an international registry. Gastroenterology 2020;159:481-91.

17. Montero F, Martinez-Barrio J, Serrano-Benavente B, Gonzalez T, Rivera J, Molina Collada J, et al. Coronavirus disease 2019 (COVID-19) in autoimmune and inflammatory conditions: clinical characteristics of poor outcomes. Rheumatol Int 2020;40:1593-8.

18. Fredi M, Cavazzana I, Moschetti L, Andreoli L, Franceschini F; Brescia Rheumatology COVID-19 Study Group. COVID-19 in patients with rheumatic diseases in northern Italy: a single-centre observational and case-control study. Lancet Rheumatol 2020;2:e549-56.

19. Waki D, Nishimura K, Tokumasu H, Kadoba K, Mukoyama H, Saito R, et al. Initial high-dose corticosteroids and renal impairment are risk factors for early severe infections in elderly patients with antineutrophil cytoplasmic autoantibody-associated vasculitis: A retrospective observational study. Medicine 2020;99:e19173.

20. Arnaldi G, Angeli A, Atkinson AB, Bertagna X, Cavagnini F, Chrousos GP, et al. Diagnosis and complications of Cushing's syndrome: A consensus statement. J Clin Endocrinol Metab 2003;88:5593-602.

21. Gentry CA, Humphrey MB, Thind SK, Hendrickson SC, Kurdgelashvili G, Williams RJ 2nd. Long-term hydroxychloroquine use in patients with rheumatic conditions and development of SARS-CoV-2 infection: a retrospective cohort study. Lancet Rheumatol 2020;2:e689-97.

22. Lofgren SM, Nicol MR, Bangdiwala AS, Pastick KA, Okafor EC, Skipper CP, et al. Safety of hydroxychloroquine among outpatient clinical trial participants for COVID-19. Open Forum Infect Dis 2020;7:ofaa500.

23. Takla M, Jeevaratnam K. Chloroquine, hydroxychloroquine, and COVID-19: Systematic review and narrative synthesis of efficacy and safety. Saudi Pharm J 2020 Nov 13 (E-pub ahead of print).

24. Rana MA, Hashmi M, Qayyum A, Pervaiz R, Saleem M, Munir MF, et al. Comparison of efficacy of dexamethasone and methylprednisolone in improving pao $2 /$ fio 2 ratio among covid-19 patients. Cureus 2020;12:e10918.

25. Fatima SA, Asif M, Khan KA, Siddique N, Khan AZ. Comparison of efficacy of dexamethasone and methylprednisolone in moderate to severe covid 19 disease. Ann Med Surg 2020;60:413-6. 